\title{
State-Dependent Cross-Linking of the M2 and M3 Segments: Functional Basis for the Alignment of $\mathrm{GABA}_{\mathrm{A}}$ and Acetylcholine Receptor M3 Segments
}

\author{
Michaela Jansen and Myles H. Akabas \\ Departments of Physiology and Biophysics and of Neuroscience, Albert Einstein College of Medicine of Yeshiva University, Bronx, New York 10461
}

\begin{abstract}
Construction of a $\mathrm{GABA}_{\mathrm{A}}$ receptor homology model based on the acetylcholine (ACh) receptor structure is complicated by the low sequence similarity between $\mathrm{GABA}_{\mathrm{A}}$ and $\mathrm{ACh} \mathrm{M} 3$ transmembrane segments that creates significant uncertainty in their alignment. We determined the orientation of the $\mathrm{GABA}_{\mathrm{A}} \mathrm{M} 2$ and M3 transmembrane segments using disulfide cross-linking. The M2 residues $\alpha 1 \mathrm{M} 266$ $\left(11^{\prime}\right)$ and $\alpha 1 \mathrm{~T} 267\left(12^{\prime}\right)$ were mutated to cysteine in either wild type or single M3 cysteine mutant ( $\alpha 1 \mathrm{~V} 297 \mathrm{C}, \alpha 1 \mathrm{~A} 300 \mathrm{C}$ to $\left.\alpha 1 \mathrm{~A} 305 \mathrm{C}\right)$ backgrounds. We assayed spontaneous and induced disulfide bond formation. Reduction with DTT significantly potentiated GABAinduced currents in $\alpha$ 1T267C-L301C and $\alpha$ 1T267C-F304C. Copper phenanthroline-induced oxidation inhibited GABA-induced currents in these mutants and in $\alpha 1 \mathrm{~T} 267 \mathrm{C}$-A305C. Intrasubunit disulfide bonds formed between these Cys pairs, implying that the $\alpha$-carbon separation was at most 5.6 $\AA$. The reactive $\alpha 1 \mathrm{M} 3$ residues (L301, F304, A305) lie on the same face of an $\alpha$-helix. The unresponsive ones (A300, I302, E303) lie on the opposite face. In the resting state, the reactive side of $\alpha 1 \mathrm{M} 3$ faces M2- $\alpha 1 \mathrm{~T} 267$. In conjunction with the ACh structure, our data indicate that alignment of $\mathrm{GABA}_{\mathrm{A}}$ and $\mathrm{ACh} \mathrm{M} 3$ requires a single gap in the $\mathrm{GABA}_{\mathrm{A}} \mathrm{M} 2-\mathrm{M} 3$ loop. In the presence of GABA, oxidation of $\alpha 1$ T267C-L301C and $\alpha 1$ T267C-F304C had no effect, but oxidation of $\alpha 1$ T267C-A305C caused a significant increase in spontaneous channel opening. We infer that, as the channel opens, the distance and/or orientation between M2- $\alpha 1 \mathrm{~T} 267$ and M3- $\alpha 1 \mathrm{~A} 305$ changes such that the disulfide bond stabilizes the open state. This begins to define the conformational motion that M2 undergoes during channel opening.
\end{abstract}

Key words: $\mathrm{GABA}_{\mathrm{A}}$ receptor; ion channel; acetylcholine receptor; disulfide cross-linking; glycine; serotonin

\section{Introduction}

$\mathrm{GABA}_{\mathrm{A}}$ receptors are members of the Cys-loop receptor superfamily of neurotransmitter-gated ion channels that includes acetylcholine, glycine, and 5- $\mathrm{HT}_{3}$ receptors (Hevers and Lüddens, 1998; Karlin, 2002; Lester et al., 2004). Many general anesthetics and drugs used to treat anxiety, epilepsy, and sleep disorders target $\mathrm{GABA}_{\mathrm{A}}$ receptors, which mediate fast inhibitory synaptic transmission. Five homologous subunits, each with an extracellular N-terminal ligand-binding domain and four $\alpha$-helical transmembrane segments (M1-M4), assemble around the central channel axis to form the receptors. The channel is lined by the five M2 segments, which are surrounded by an outer ring of helices, formed by the M1, M3, and M4 segments (Xu and Akabas, 1996; Miyazawa et al., 2003).

Recently, $\mathrm{GABA}_{\mathrm{A}}$ receptor homology models (Cromer et al., 2002; Trudell and Bertaccini, 2004; Ernst et al., 2005) were con-

Received Jan. 17, 2006; revised March 20, 2006; accepted March 20, 2006.

This work was supported in part by National Institutes of Health Grants NS30808 and GM77660 (M.H.A.). M.J. was supported in part by a fellowship from the Deutsche Forschungsgemeinschaft. We thank Moez Bali, David Liebelt, Nicole McKinnon, David Reeves, and Paul Riegelhaupt for helpful discussions and also for comments on this manuscript.

Correspondence should be addressed to Dr. Myles H. Akabas, Department of Physiology and Biophysics, Albert Einstein College of Medicine, Bronx, NY 10461. E-mail: makabas@aecom.yu.edu.

DOI:10.1523/JNEUROSCI.0224-06.2006

Copyright $\odot 2006$ Society for Neuroscience $\quad$ 0270-6474/06/264492-08\$15.00/0 structed based on the acetylcholine binding protein and Torpedo ACh receptor structures (Brejc et al., 2001; Miyazawa et al., 2003; Celie et al., 2004; Unwin, 2005). Homology models depend on the correct alignment of subunit sequences from different superfamily members. Uncertainty in sequence alignment limits the veracity of models. Alignment of ACh and $\mathrm{GABA}_{\mathrm{A}} \mathrm{M} 1$ and M2 transmembrane segments is facilitated by highly conserved residues corresponding to $\mathrm{GABA}_{\mathrm{A}} \alpha 1 \mathrm{R} 221, \alpha 1 \mathrm{P} 233, \alpha 1 \mathrm{~F} 245$, $\alpha 1 \mathrm{R} 255, \alpha 1 \mathrm{~L} 264$, and $\alpha 1 \mathrm{P} 278$ (Fig. 1) (Le Novere and Changeux, 1999; Ernst et al., 2005). M3 segment alignment is more complicated, because they are mostly hydrophobic with very limited sequence identity (Fig. 1). Thus, multiple sequence alignment programs introduce a variable number of gaps in the $\mathrm{GABA}_{\mathrm{A}}$ M2-M3 loop relative to the ACh receptor depending on the number of sequences and the specific subunits that are aligned. Progress in generating correct homology models requires an experimental determination of both the face of the $\mathrm{GABA}_{\mathrm{A}} \mathrm{M} 3$ segment that interacts with M2 and the vertical position of M3 relative to defined levels in M2. Having the correct structural model is essential to understanding the molecular basis for general anesthetic and alcohol action on $\mathrm{GABA}_{\mathrm{A}}$ receptors.

In the current work, we determined the proximity of M2 and M3 residues using disulfide cross-linking between pairs of engineered cysteines. We used two M2 positions, $\alpha 1 \mathrm{M} 266$ (11') and $\alpha 1 \mathrm{~T} 267$ (12'), that we showed lie opposite to the M2 channel- 
GABA $\alpha_{1}$

GABA $\beta_{1}$

GABA $\gamma_{2}$

Gly $\alpha_{1}$

Gly $\beta_{1}$

$5 \mathrm{HT}_{\mathrm{A}}$

$5 \mathrm{HT}_{\mathrm{B}}$

nACh $\alpha_{1}$

nACh $\beta_{1}$

nACh $\delta_{1}$

nACh $\varepsilon_{1}$

nACh $\gamma_{1}$

nACh $\beta$ torma

nACh $\delta$ torma

nACh $\vee$ torma
233 PCIMTVILSQ VSFWLNRESV PARTVFGVTT

228 PSTLITILSW VSFWINYDAS AARVALGITT

243 PCTLIVVLSW VSFWINKDAV PARTSLGITT

230 PSLLIVILSW ISFWINMDAA PARVGLGITT

254 PTLLIVVLSW LSFWINPDAS AARVPLGIES

233 PSIFLMVVDI VGFCLPPDSG -ERVSFKITL

223 PSTETMTVDT GSFYI PPNCR

220 PCLLFSFLTS LVFYLPTDSG

231 PCILITLLAI FVFYLPPDAG

234 PCVITSETN IVFYI PGDCG -EKTSVAISV

230 PCVLISGLVL LAYFLPAQAG

229 PCVLISSVAI LIYFLPAKAG

220 PCLLFSFLTV LVFYLPTDSG

226 PCILISILAI LVFYLPPDAG

234 PCVLISFLAA LAFYLPAESG

8 PCVLISSLVV LVYFLPAQA
VLTMTTLSIS ARNSLPKVAY

NTTSTH LRETLPKIPY VK-AIDIYLM GCFVFVFLAL LEYAFVNYIF 306

VLTMTTLSTI ARKSLPKVSY VT-AMDLFVS VCFIEVESAL VEYGTLHYEV 321

VLTMTTQSSG SRASLPKVSY VK-AIDIWMA VCLLFVFSAL LEYAAVNFVS 308

VLSLASECTT LAAELPKVSY VK-ALDVWLI ACLLFGFASL VEYAVVQVML 332 GYVELII VSDTLPATAI GTPLIGVYFV VCMALLVISL AETIFIVQLV 312 LVGYTVFRVN MSDEVPRSAG CTSLIGVFFT VCMALLVLSL SKSILLIKFL 302 LLSLTVELLV IVELIPSTSS AVPLIGKYML FTMVFVIASI IITVIVINTH 299 LLTLTVELLL LADKVPETSL AVPIIIKYLM FTMILVTESV ILSVVVLNLH 310 LLAQSVFLLL ISKRLPATSM AIPLVGKFLL FGMVLVTMVV VICVIVLNIH 313 NV LLAQTVFLFL IAQKIPETSL SVPLLGRYLI FVMVVATLIV MNCVIVLNVS 309 GQKCTVATNV LLAQTVFLFL VAKKVPETSQ AVPLISKYLT FLMVVTILIV VNSVVVLNVS 308
-EKMTLSISV LLSLTVFLLV IVELIPSTSS AVPLIGKYML FTMIFVISSI IVTVVVINTH 299 -EKMSLSISA LLALTVFLLL LADKVPETSL SVPIIISYLM FIMILVAFSV ILSVVVLNLH 305 -EKMSTAICV LLAQAVFLLL TSQRLPETAL AVPLIGKYLM FIMSLVTGVV VNCGIVLNFH 313 GQKCTLSISV LLAQTIFLFL IAQKVPETSL NVPLIGKYLI FVMFVSLVIV TNCVIVLNVS 307 $::$ : : :

Figure 1. Alignment of $\mathrm{GABA}_{\mathrm{A}}, \mathrm{Gly}, 5-\mathrm{HT}_{3}$, and $\mathrm{ACh}$ receptor subunit sequences. The lines on top indicate TM regions based on the extents of the TM segments in the $4 \AA \mathrm{ACh}$ receptor structure (Unwin, 2005). Residues in the $\mathrm{GABA}_{\mathrm{A}} \alpha 1$ subunit that were mutated in this study are underlined and in bold. The extent of amino acid conservation at each position is indicated below the sequences: absolutely conserved $\left({ }^{*}\right)$, highly conserved (:), and moderately conserved (.). All sequences are the rat sequences except for the bottom four AChR subunits labeled "torma," which are from $T$. marmorata.

lining face (Xu and Akabas, 1996). In the ACh receptor structure, the aligned residues are in close proximity to $\mathrm{M} 1$ and $\mathrm{M} 3$, respectively (Miyazawa et al., 2003). Based on the ACh receptor structure, $\mathrm{GABA}_{\mathrm{A}} \mathrm{M} 3$ residues between $\alpha 1 \mathrm{~A} 300$ and $\alpha 1 \mathrm{~A} 305$ should lie in close proximity to $\alpha 1$ T267. We constructed all of the double cysteine mutants between these M2 and M3 positions and assayed for spontaneous and induced disulfide bond formation in the absence and presence of GABA. Two M3 positions formed disulfide bonds in the closed state but not in the presence of GABA. Disulfide bond formation with a third position in the presence of GABA significantly increased the channels' spontaneous open probability. These results provide insight into the resting state structure and the conformational motion between M2 and M3 during channel gating in the Cys-loop receptor superfamily.

\section{Materials and Methods}

Alignment. Sequences were obtained from UniProt (Universal Protein Resource; http://www.ebi.uniprot.org/index.shtml) or RCSB PDB (Research Collaboratory for Structural Bioinformatics; http://www.rcsb. org/pdb/), and aligned using ClustalW (http://www.ebi.ac.uk/clustalw/ index.html). To improve the reliability of the alignment, we performed a multiple alignment with several other members of the Cys-loop superfamily of ligand-gated ion channels.

Mutagenesis and oocyte expression. M2 segment residues can be named using an index numbering system that facilitates comparison between M2 segments of different members of the superfamily. At the cytoplasmic end, the $0^{\prime}$ position is defined as the conserved positively charged residue aligned with $\mathrm{GABA}_{\mathrm{A}} \alpha 1 \mathrm{R} 255$, and the $20^{\prime}$ position (Miller, 1989) is the residue aligned with the $\mathrm{ACh}$ receptor extracellular ring of charge (Imoto et al., 1988). The rat $\mathrm{GABA}_{\mathrm{A}}$ receptor $\alpha 1, \beta 1$, and $\gamma 2 \mathrm{~S}$ subunit cDNA constructs in the pGEMHE vector were used. The M2 mutations were introduced using $\alpha 1$ wild-type (wt) or $\alpha 1 \mathrm{M} 3$ single mutants (V297C, A300C, L301C, I302C, E303C, F304C, A305C) as templates (Williams and Akabas, 1999) and the QuikChange mutagenesis kit (Stratagene, La Jolla, CA). Mutational primers (Sigma, St. Louis, MO) introduced M266C (5'-GTG ACG ACC GTT CTG ACC TGT ACA ACC TTG AGT ATC AGT GC-3' and $3^{\prime}$-GCA CTG ATA CTC AAG GTT GTA CAG GTC AGA ACG GTC GTC AC-5') or T267C ( $5^{\prime}$-ACG ACC GTT CTG ACC ATG TGT ACA TTG AGT ATC AGT GCC AG-3' and 3' -CTG GCA CTG ATA CTC AAT GTA CAC ATG GTC AGA ACG GTC GT-5' ${ }^{\prime}$ ) and a silent $B s r$ GI site (mutated base pairs in bold; BsrGI recognition site underlined). The identity was verified by restriction digestion and DNA sequencing of the complete coding region. Plasmids were linearized with
NheI before in vitro mRNA transcription with T7 RNA polymerase (Amplicap T7 High Yield Message Maker; Epicenter Technologies, Madison, WI; or mMessage mMachine kit; Ambion, Austin, TX). mRNA was dissolved in diethylpyrocarbamate-treated water and stored at $-80^{\circ} \mathrm{C}$. Female Xenopus laevis were purchased from Nasco Science (Fort Atkinson, WI). Stage V-VI oocytes were defolliculated with a 75 min incubation in $2 \mathrm{mg} / \mathrm{ml}$ Type 1A collagenase (Sigma) in OR2 ( $82.5 \mathrm{~mm} \mathrm{NaCl}, 2$ mм KCl, $1 \mathrm{~mm} \mathrm{MgCl}_{2}$, and 5 mм HEPES; $\mathrm{pH}$ adjusted to 7.5 with $\mathrm{NaOH}$ ). Oocytes were washed thoroughly in OR2 and kept in SOS medium (82.5 $\mathrm{mm} \mathrm{NaCl}, 2.5 \mathrm{~mm} \mathrm{KCl}, 1 \mathrm{~mm} \mathrm{MgCl}_{2}, 5 \mathrm{~mm}$ HEPES, pH 7.5) supplemented with $1 \%$ antibiotic-antimycotic $(100 \times)$ liquid $(10,000 \mathrm{IU} / \mathrm{ml}$ penicillin, 10,000 $\mu \mathrm{g} / \mathrm{ml}$ streptomycin, and $25 \mu \mathrm{g} / \mathrm{ml}$ amphotericin B; Invitrogen, Carlsbad, CA) and 5\% horse serum (Sigma). Oocytes were injected $24 \mathrm{~h}$ after isolation with $50 \mathrm{nl}(10 \mathrm{ng})$ of a 1:1:1 mixture of rat $\alpha 1: \beta 1: \gamma 2 S$ subunit mRNA and were kept in horse serum medium for $2-10 \mathrm{~d}$ at $17^{\circ} \mathrm{C}$. Mutant subunit mRNA was substituted for wt $\alpha 1$ subunit where necessary (Horenstein et al., 2001).

Electrophysiology. Electrophysiological recordings were conducted at room temperature in a $\sim 250 \mu \mathrm{l}$ chamber continuously perfused at a rate of 5-6 ml/min with $\mathrm{Ca}^{2+}$-free frog Ringer's buffer (CFFR) (115 mM $\mathrm{NaCl}, 2.5 \mathrm{~mm} \mathrm{KCl}, 1.8 \mathrm{~mm} \mathrm{MgCl}_{2}, 10 \mathrm{~mm}$ HEPES, pH 7.5 with $\mathrm{NaOH}$ ) using equipment and procedures described previously (Horenstein and Akabas, 1998). Currents were recorded from individual oocytes using two-electrode voltage-clamp at a holding potential of $-60 \mathrm{mV}$. The ground electrode was connected to the bath via a $3 \mathrm{M} \mathrm{KCl} /$ Agar bridge. Glass microelectrodes had a resistance of $<2 \mathrm{M} \Omega$ when filled with $3 \mathrm{M}$ $\mathrm{KCl}$. Data were acquired and analyzed using a TEV-200 amplifier (Dagan Instruments, Minneapolis, MN), a Digidata 1322A data interface (Molecular Devices, Union City, CA), and pClamp 8 software (Molecular Devices). Currents $\left(I_{\mathrm{GABA}}\right)$ elicited by GABA applications were separated by at least 6 min of CFFR wash to allow complete recovery from desensitization. Currents were judged to be stable if the variation between consecutive GABA pulses was $\leq 10 \%$.

Reagents. GABA (Sigma) was prepared as a $100 \mathrm{~mm}$ stock solution in water. Dithiothreitol (DTT) (Sigma) was dissolved in water to obtain a 1 $\mathrm{M}$ stock solution and diluted into CFFR before each experiment. $o$-Phenanthroline (Sigma) was made as a $1 \mathrm{M}$ stock solution in DMSO and $\mathrm{CuSO}_{4}$ as a $100 \mathrm{~mm}$ stock solution in water. $\mathrm{CuSO}_{4}$ and $o$-phenanthroline were mixed in CFFR before use to a final concentration of 100:200 $\mu \mathrm{M}$ or 10:20 $\mu \mathrm{M}$ Cu:Phen. Tris(2-carboxyethyl)phosphine $\mathrm{HCl}$ (TCEP) (Sigma) was dissolved in water to obtain a $100 \mathrm{~mm}$ stock and diluted into CFFR before each experiment. Picrotoxin was dissolved in DMSO at a $100 \mathrm{~mm}$ concentration and diluted in CFFR.

DTT effect. Once stable $\mathrm{GABA} \mathrm{EC}_{30-50}$ test currents $(I)$ were achieved, $10 \mathrm{~mm}$ DTT was applied for $2 \mathrm{~min}$. After a washout period of $6 \mathrm{~min}$ the 
GABA EC $E_{30-50}$ test current was recorded again $\left(I_{\mathrm{DTT}}\right)$. Potentiation by application of DTT was calculated as follows: effect $\%=\left\{\left(I_{\mathrm{DTT}}-I\right) /\right.$ $\left.I_{\text {DTT }}\right\} \times 100$.

Cu:Phen effect. Oocytes were pretreated with DTT and GABA test pulses $\left(I_{\text {DTT }}\right)$ were applied. Oocytes were then treated with 100:200 $\mu \mathrm{M}$ $\mathrm{Cu}$ :Phen for $2 \mathrm{~min}$, and two more GABA test pulses were applied $\left(I_{\mathrm{Cu}}\right.$ Phen). A second application of $10 \mathrm{~mm}$ DTT for 2 min followed by GABA test pulses was used to test for the reversibility of the Cu:Phen effect. Inhibition by $\mathrm{Cu}$ :Phen induced disulfide bonds was calculated as follows: effect $\%=\left\{\left(I_{\text {Cu:Phen }}-I_{\text {DTT }}\right) / I_{\text {DTT }}\right\} \times 100$.

$C u$ :Phen effect in the presence of GABA, open/desensitized states. For this set of experiments, we first determined the minimum application duration of 10:20 $\mu \mathrm{M} \mathrm{Cu}$ :Phen that produces inhibition comparable with a 2 min application of 100:200 $\mu \mathrm{M} \mathrm{Cu}$ :Phen. Preliminary experiments with the $\alpha 1$ T267C L301C double mutant on initially fully reduced $(10 \mathrm{~mm}$ DTT; 2 min) oocytes using alternating applications of 10:20 $\mu \mathrm{M} \mathrm{Cu}$ :Phen for $1 \mathrm{~min}$ and $\mathrm{GABA} \mathrm{EC} \mathrm{E}_{30}$ test currents showed that a comparable effect to the application of 100:200 $\mu \mathrm{M} \mathrm{Cu}$ :Phen for $2 \mathrm{~min}$ was reached after a cumulative exposure to 10:20 $\mu \mathrm{M} \mathrm{Cu}$ :Phen of $2 \mathrm{~min}$.

To determine whether disulfide bonds were formed in the open state, we performed the following experiment: Once stable $\mathrm{GABA} \mathrm{EC}_{30-50}$ test currents $(I)$ were achieved, we applied $10 \mathrm{~mm}$ DTT for $2 \mathrm{~min}$. The GABA $\mathrm{EC}_{30-50}$ test current was recorded again $\left(I_{\mathrm{DTT}}\right)$ to determine the extent of spontaneously formed disulfide bonds. After a $20 \mathrm{~s} \mathrm{GABA} \mathrm{EC}_{\max }$ pulse, cells were immediately treated with a mixture of the same GABA concentration and 10:20 $\mu \mathrm{M} \mathrm{Cu}$ :Phen for $2 \mathrm{~min}$. After washout of the reagents, two more GABA test pulses were applied $\left(I_{\mathrm{Cu} \text { :Phen }}+\mathrm{GABA}\right)$. A second application of $10 \mathrm{~mm}$ DTT for $2 \mathrm{~min}$ followed by GABA test pulses was used to test for the reversibility of the Cu:Phen effect. Inhibition by disulfide bonds formed in the presence of GABA and $\mathrm{Cu}$ :Phen was cal-

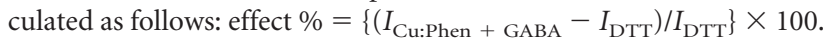

$\mathrm{Cu}$ :Phen induced oxidation was performed for each oocyte in the absence and in the presence of GABA. One-half of the oocytes were first oxidized in the presence and then in the absence of GABA, the other one-half in the reverse order.

Homology modeling. The membrane-spanning domain of the rat $\mathrm{GABA}_{\mathrm{A}}$ receptor $\alpha 1$ subunit was modeled on the basis of the $4 \AA$ structure obtained by electron microscopy of crystalline postsynaptic membranes with pentameric ACh receptors of Torpedo marmorata [Protein Data Bank (PDB) number 2BG9]. Using Deep View/Swiss Pdb-Viewer, version 3.7 (Guex and Peitsch, 1997; Schwede et al., 2003), we aligned the GABA $\alpha 1$ subunit sequence with the ACh E chain ( $\gamma$ chain) manually, taking the alignment that we obtained with ClustalW, as outlined above, into account. We generated two different models, one without a gap and one with a 1 aa gap in the M2-M3 loop in the GABA $\alpha 1$ sequence compared with the ACh E chain ( $\gamma$ chain) sequence. The ACh structure aligned with the raw sequence was submitted as a modeling request in Swiss Model. The resulting homology modeled $\alpha 1$ structure was subsequently subjected to energy minimization using the GROMOS 43B1 force field in vacuo that is part of Swiss-PdbViewer. Figures were rendered with POV-Ray v3.6 (http://www.povray.org/) (Bali and Akabas, 2004).

\section{Results}

\section{Effect of DTT on wt and mutant 12' Cys receptors}

In electrophysiological experiments, we recorded GABAinduced currents $\left(I_{\mathrm{GABA}}\right)$ from oocytes expressing GABA $\alpha 1 \beta 1 \gamma 2$ receptors. Where applicable, the $\alpha 1$ wt subunit was substituted by mutant $\alpha 1$ subunits, containing a single engineered Cys in M2 ( $11^{\prime}$ or $12^{\prime}$ Cys) or two engineered Cys [one in M2 (11' or 12' Cys) and one in M3]. DTT is a disulfide bond-reducing agent. It contains two sulfhydryl moieties and is thus able to convert protein disulfides to sulfhydryls via a thiol-disulfide exchange reaction. In wt $\alpha 1 \beta 1 \gamma 2$ receptors, DTT potentiated GABA-induced currents by $14 \pm 4 \%(n=6)$ (Fig. 2$)$. Under the same conditions, the single mutant $\alpha 1 \mathrm{~T} 267 \mathrm{C}$, and the double mutants $\alpha 1 \mathrm{~T} 267 \mathrm{C}$ A300C, $\alpha 1$ T267C-I302C, $\alpha 1$ T267C-E303C, and $\alpha 1 \mathrm{~T} 267 \mathrm{C}-$ A305C were not significantly different from wt (one-way

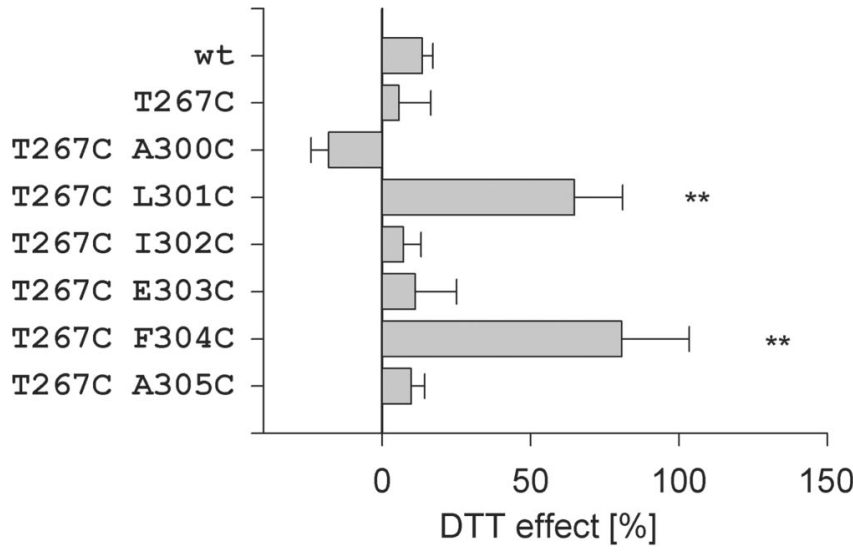

Figure 2. The average effect of a 2 min application of $10 \mathrm{~mm}$ DTT on wt and $12^{\prime}$ Cys mutants. A positive effect indicates potentiation, and a negative effect indicates inhibition of subsequent GABA-induced currents. The asterisks indicate effects that are significantly different from the effect on wt by a one-way ANOVA, using Dunnett's multiple comparison test, $p<0.001$. For each condition, the results of three to eight oocytes are averaged. Means \pm SEM are shown.

ANOVA; Dunnett's multiple comparison test; $p>0.05)$. However, the currents in the double mutants $\alpha 1 \mathrm{~T} 267 \mathrm{C}-\mathrm{L} 301 \mathrm{C}$ and $\alpha 1 \mathrm{~T} 267 \mathrm{C}-\mathrm{F} 304 \mathrm{C}$ were potentiated by $71 \pm 25 \%(n=6)$ and $81 \pm$ $32 \%(n=8)$, respectively. The potentiation in the double mutants $\alpha 1$ T267C-L301C and $\alpha 1$ T267C-F304C was significantly different from wt receptors (one-way ANOVA; Dunnett's multiple comparison test; $p<0.05$ and $p<0.01$ ) (Fig. 2) and may be explained by the reduction of a spontaneously formed disulfide bond between the engineered Cys in M2 and M3. If a disulfide bond were to be formed between these Cys, the relative mobility of at least the M2 and M3 $\alpha$-helices would be diminished, thus impairing receptor function.

\section{Effect of Cu:Phen on wt and mutant 12' Cys mutants}

Under aerobic conditions (oxygen dissolved in CFFR) (with $\mathrm{Cu}$ :Phen in a molar ratio of 1:2 serving as a catalyst), oxygen oxidizes the sulfhydryl groups selectively to disulfides but rarely to higher oxidized states (Kobashi, 1968). We tested the effect of Cu:Phen (100:200 $\mu \mathrm{M} ; 2 \mathrm{~min})$ on fully reduced wt and $12^{\prime}$ Cys single and double mutant receptors. To reduce spontaneously formed disulfide bonds between engineered Cys pairs or between engineered Cys and small endogenous sulfhydryls like cysteine and glutathione, oocytes were first treated with DTT (10 mm; 2 min). Cystine and GSSG (oxidized glutathione) participate in disulfide interchange reactions and are capable of forming mixed disulfides with proteins. After DTT application, oocytes were allowed to equilibrate with CFFR, and GABA pulses were recorded with a frequency of one per 6 min. Subsequently, cells were treated with Cu:Phen (100:200 $\mu \mathrm{M} ; 2 \mathrm{~min}$ ), and after a washout period, the resulting GABAinduced currents were recorded (Fig. 3). There was no effect of oxidation neither in wt receptors, nor the $12^{\prime}$ single mutant $\alpha 1 \mathrm{~T} 267 \mathrm{C}$, nor in the double mutants $\alpha 1 \mathrm{~T} 267 \mathrm{C}-\mathrm{V} 297 \mathrm{C}$, $\alpha 1$ T267C-A300C, $\alpha 1$ T267C-I302C, and $\alpha 1$ T267C-E303C. $\mathrm{Cu}:$ Phen inhibited GABA-induced currents in wt, $\alpha 1 \mathrm{~T} 267 \mathrm{C}$, $\alpha 1$ T267C-A300C, $\alpha 1$ T267C-I302C, and $\alpha 1$ T267C-E303C by $11 \pm 4 \%(n=6), 8 \pm 7 \%(n=5), 3 \pm 4 \%(n=3), 15 \pm 5 \%$ $(n=5), 1 \pm 16 \%(n=5)$ (one-way ANOVA; $p>0.05)$. However, the double mutants that were potentiated by DTT, namely $\alpha 1$ T267C-L301C and $\alpha 1$ T267C-F304C, and in addition also $\alpha 1$ T267C-A305C (Fig. 3E) showed an inhibition of $45 \pm 2 \%(n=18), 45 \pm 4 \%(n=11)$, and $55 \pm 7 \%(n=5)$, 
A

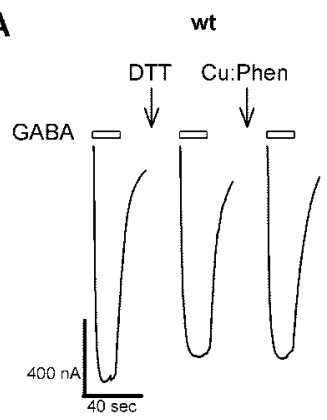

\section{E}

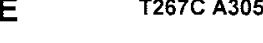

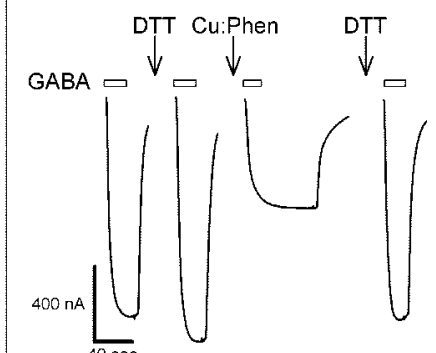

C

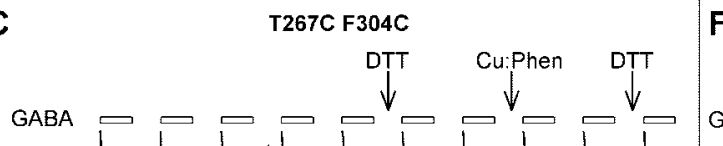

F T267C L301C

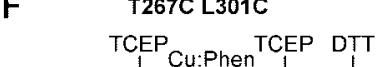

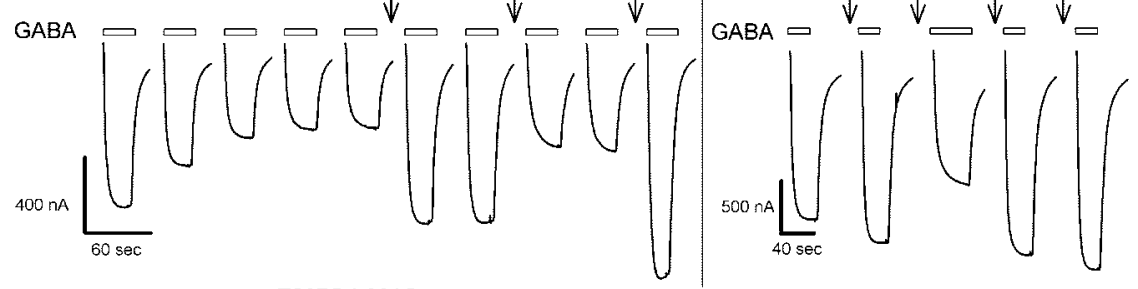

D

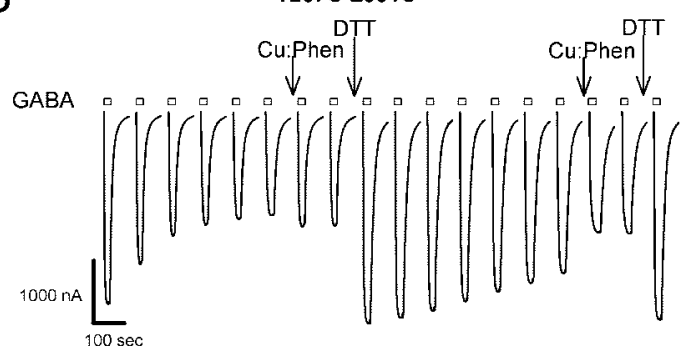

Figure 3. DTT/TCEP and Cu:Phen effect on wt and $\alpha 1-12^{\prime}$ Cys mutants. GABA-induced current traces before and after 2 min applications of $10 \mathrm{~mm}$ DTT or 100:200 $\mu \mathrm{m}$ Cu:Phen from wt and mutant receptors are shown. $\boldsymbol{A}$, Wild-type $\alpha 1 \beta 1 \gamma 2 S$ are not significantly affected by either DTT or Cu:Phen. $\boldsymbol{B}, \alpha 1$ T267C-E303C $\beta 1 \gamma 2 S$ are not significantly affected by either DTT or Cu:Phen. C, D, $\alpha 1$ T267C-F304C (C) and $\alpha 1$ T267C-L301C (D) show spontaneous disulfide bond formation that is reversed by DTT and induced by Cu:Phen. In $\alpha 1 T 267 \mathrm{C}-\mathrm{L} 301 \mathrm{C}$-containing receptors, the current size decreases with each GABA pulse. After reaching a stable plateau, current can be recovered to the initial size after reduction with DTT. A Cu:Phen application inhibits currents to the same extent as reached after repetitive GABA applications. This inhibition is DTT reversible. $E$, In $\alpha 1$ T267C-A305C-containing receptors, DTT application does not significantly alter the subsequent current. Cu:Phen, however, significantly inhibits these receptors. This inhibition is reversed by DTT application. $F, \alpha 1 T 267 \mathrm{C}-\mathrm{L} 301 \mathrm{C}$ can be cycled between reduced and oxidized states by reducing with TCEP (1 mm; $2 \mathrm{~min}$ ) and oxidizing with Cu:Phen (100:200 $\mu \mathrm{m} ; 2 \mathrm{~min})$. DTT (10 mm; $2 \mathrm{~min}$ ) does not significantly potentiate TCEP-treated oocytes. All traces are separated by 6 min washes with CFFR from reagent or GABA applications to allow for washout of excess reagents or complete recovery from desensitization. All GABA current traces represent stable currents: two subsequent GABA currents were not different by $>10 \%$. Currents during reagent application are not shown. The bars above the traces indicate the duration of GABA applications; the arrows indicate the application of the indicated reagent.

respectively, that was significantly different from wt (one-way ANOVA; Dunnett's multiple comparison test; $p<0.001$ ) (Fig. 4). The $\mathrm{Cu}$ :Phen-induced inhibition of GABA currents could be fully reversed by a second application of DTT. The ability to reverse the $\mathrm{Cu}$ :Phen inhibition with DTT implies that it is attributable to disulfide bond formation and not attributable to oxidation of one or both of the Cys to a higher-order oxidation state that would not be reducible by DTT. We infer that, by alternatively applying DTT and Cu:Phen, we cycle between fully reduced (free sulfhydryls) and fully oxidized (disulfide-bonded) receptors and that the inhibition in the oxidized state is caused by a disulfide bond that cross-links the engineered Cys in M2 and M3.

Spontaneous formation of disulfide bonds, in the absence of $\mathrm{Cu}:$ Phen, was often recorded after GABA applications in the receptors $\alpha 1$ T267C L301C and $\alpha 1$ T267C F304C (Fig. 3D). After stabilization of the current, further oxidation using Cu:Phen (100:200 $\mu \mathrm{M} ; 2 \mathrm{~min})$ did not lead to any additional inhibition of GABA-induced currents. Reduction by DTT increased the GABA-induced currents to at least their initial size. In turn, this increase could be reversed by oxidation with $\mathrm{Cu}: P h e n$. This spontaneous decrease in the GABA-induced current was not observed in all the oocytes. In some oocytes, the initial current was as big as after DTT application, whereas in others the initial current was as inhibited as after $\mathrm{Cu}$ :Phen application. We infer that these differences are attributable to changes in the redox environment of different batches of oocytes, thus leading to varying degrees of spontaneously formed disulfide bonds.

For $\alpha 1 \mathrm{~T} 267 \mathrm{C}-\mathrm{L} 301 \mathrm{C}$ and $\alpha 1 \mathrm{~T} 267 \mathrm{C}$ F304C, we also determined whether the inhibition by $\mathrm{Cu}$ :Phen (100:200 $\mu \mathrm{M} ; 2$ $\mathrm{min}$ ) could be reversed by application of TCEP (Fig. 3E). TCEP is a reducing agent that, contrary to DTT, forms only weak complexes with heavy metals (Krezel et al., 2003). Thus, if after TCEP application GABA-induced currents are potentiated, this can only be caused by reduction of disulfide bonds and not by chelating heavy metals. After a $2 \mathrm{~min} \mathrm{Cu}$ : Phen application (100:200 $\mu \mathrm{M})$, $\alpha 1 \mathrm{~T} 267 \mathrm{C}-\mathrm{A} 301 \mathrm{C}$ receptors were inhibited by $52 \pm 2 \%(n=3)$ and $\alpha 1$ T267CF304C receptors by $60 \pm 2 \%(n=5)$. This inhibition could be reversed by a 1 min treatment with $2 \mathrm{~mm}$ TCEP. A subsequent application of DTT did not potentiate GABA currents any further $(\alpha 1 \mathrm{~T} 267 \mathrm{C}-\mathrm{A} 301 \mathrm{C}: 0 \pm 5 \%, n=3$; $\alpha 1 \mathrm{~T} 267 \mathrm{C}-\mathrm{F} 304 \mathrm{C}:-7 \pm 2 \%, n=5)$. We infer that both the $\alpha 1 \mathrm{~T} 267 \mathrm{C}-\mathrm{A} 301 \mathrm{C}$ and the $\alpha 1 \mathrm{~T} 267 \mathrm{C}-\mathrm{F} 304 \mathrm{C}$ disulfide bond are accessible for both the smaller and membrane-permeant DTT and for the larger and triple negatively charged, and thus membrane-impermeant, TCEP.

\section{Cu:Phen effect on the 12' mutants $\alpha 1$ T267C-L301C, $\alpha 1$ T267C-F304C, and $\alpha 1$ T267C-A305C in the absence and presence of GABA}

In the absence of GABA, the channels are primarily in the closed, unliganded state. In the presence of GABA, the channels undergo rapid transitions between the open, desensitized and closed states. In addition, there are multiple open and desensitized states. Given the timescale of the transitions (milliseconds) and the timescale of the experiments (tens of seconds), we cannot distinguish in which state disulfide bond formation is occurring in the presence of GABA.

We examined the effect of agonist coapplication on $\mathrm{Cu}$ :Pheninduced disulfide bond formation. The effect of 10:20 $\mu \mathrm{M} \mathrm{Cu}$ : Phen on $\alpha 1$ T267C-L301C and $\alpha 1$ T267C-F304C containing receptors was abolished when it was coapplied with GABA. The 


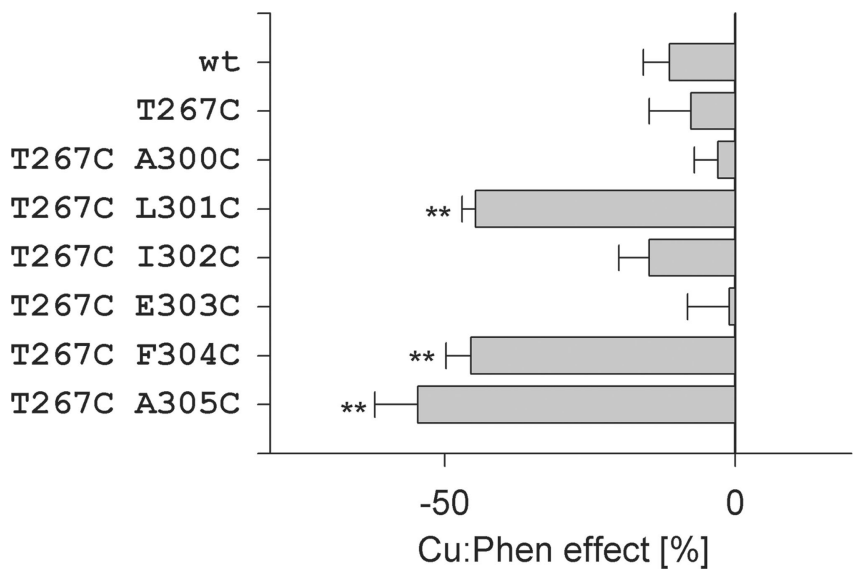

Figure 4. The average effect of a 2 min application of 100:200 $\mu \mathrm{m}$ Cu:Phen on wt and 12' Cys mutants. A positive effect indicates potentiation, and a negative effect indicates inhibition of subsequent GABA-induced currents. The asterisks indicate effects that are significantly different from the effect on wt by a one-way ANOVA, using Dunnett's multiple comparison test, $p<$ 0.001 . For each condition, the results of 3-18 0ocytes are averaged. Means \pm SEM are shown.

double mutant $\alpha 1$ T267C-L301C was inhibited by $36 \pm 2 \%(n=4)$ by applying Cu:Phen (10:20 $\mu \mathrm{M} ; 2 \mathrm{~min})$ alone compared with $7 \pm$ $4 \%(n=4)$ by applying Cu:Phen $(10: 20 \mu \mathrm{m} ; 2 \mathrm{~min})$ in the presence of a saturating GABA concentration. When compared with a paired $t$ test, the effect in the closed state is significantly different from the one in the open state $(p=0.015)$. The $\alpha 1$ T267C-F304C receptors were inhibited by $31 \pm 1 \%(n=4)$ by applying $\mathrm{Cu}$ : Phen alone and by $-12 \pm 6 \%(n=4)$ by applying $\mathrm{Cu}:$ Phen together with GABA (paired $t$ test; $p=0.0057$ ). The propensity to form a disulfide bond in the closed state is increased for $\alpha 1$ T267C-L301C and $\alpha$ 1T267C-F304C.

In contrast to these two double mutants, the amount of inhibition of the GABA peak currents for the $\alpha 1$ T267C-A305C mutant increased from $26 \pm 3 \%(n=4)$ with $\mathrm{Cu}$ :Phen alone to $67 \pm$ $6 \%(n=4)$ for $\mathrm{Cu}$ :Phen in the presence of GABA (paired $t$ test; $p=0.0012)$. We conclude that the distance/relative orientation of the 12' Cys in M2 and the 305Cys in M3 is different in the closed (absence of GABA) and open/desensitized (presence of GABA) states. In the double mutant, $\alpha 1$ T267C-A305C, a significant change in leak current was induced by coapplication of $\mathrm{Cu}$ :Phen with GABA, but not by $\mathrm{Cu}$ :Phen alone (Fig. $5 C$ ). Subsequent treatment with DTT reversed both the increase in leak current and also the decrease in GABA-induced current amplitude. The increase in leak current could be transiently blocked by applying the open channel blocker picrotoxin (50 $\mu \mathrm{M})$ (Fig. $5 D)$. We infer that, when $\alpha 1$ T267C-A305C is oxidized in the open state, the receptor is trapped in a conformation for which the spontaneous open probability is increased. Therefore, the current amplitude that can result from GABA application is decreased. If the increase in leak current after a combined GABA$\mathrm{Cu}$ :Phen application is added to the GABA current amplitude after the Cu:Phen plus GABA application, the inhibition would be $24 \pm 7 \%(n=4)$, which is comparable with the inhibition caused by application of $\mathrm{Cu}$ :Phen alone.

\section{Effect of DTT and Cu:Phen on $\alpha 1$ T267C-V297C}

We sought to test the extent of vertical motion of $\mathrm{M} 3$ relative to the $12^{\prime}$ M2 position. V297 lies on the same face of the M3 helix as the reactive residues but one helical turn closer to the extracellular side. Application of $10 \mathrm{~mm}$ DTT for $2 \mathrm{~min}$ or 100:200 $\mu \mathrm{M}$ $\mathrm{Cu}$ :Phen for $2 \mathrm{~min}$ had no effect on the GABA-induced currents of the double mutant $\alpha 1$ T267C-V297C. We infer that a disulfide bond does not form between these two residues, implying that there is limited vertical motion of the M3 segment relative to the M2 segment.

\section{Cu:Phen effect on the 11' mutants $\alpha 1 \mathrm{M} 266 \mathrm{C}-\mathrm{L} 301 \mathrm{C}$, $\alpha 1 \mathrm{M} 266 \mathrm{C}-\mathrm{F} 304 \mathrm{C}$, and $\alpha 1 \mathrm{M} 266 \mathrm{C}-\mathrm{A} 305 \mathrm{C}$ in the absence and presence of GABA}

As a control for possible reaction of the M3 Cys with endogenous cysteines, we tested the effects of DTT and Cu:Phen on the redoxsensitive M3 Cys mutants in the presence of the 11' Cys mutant $\alpha 1 \mathrm{M} 266 \mathrm{C}$. A $2 \mathrm{~min}$ application of $10 \mathrm{~mm}$ DTT had no significant effects on the subsequent GABA-induced currents in oocytes expressing the mutants $\alpha 1 \mathrm{M} 266 \mathrm{C}, \alpha 1 \mathrm{M} 266 \mathrm{C}-\mathrm{L} 301 \mathrm{C}, \alpha 1 \mathrm{M} 266 \mathrm{C}$ F304C, or $\alpha 1 \mathrm{M} 266 \mathrm{C}-\mathrm{A} 305 \mathrm{C}$ compared with wild type (one-way ANOVA with Dunnett's multiple comparison test; $p>0.05$ ) (data not shown). We infer that no disulfide bonds formed spontaneously between these pairs of Cys mutants or between these Cys mutants and the endogenous cysteines.

We also tested the effect of oxidation on these mutants with a 2 min application of 100:200 $\mu \mathrm{M} \mathrm{Cu}$ :Phen to oocytes expressing these mutants in the absence and presence of GABA. There was no significant effect on the subsequent GABA-induced currents compared with wild type (one-way ANOVA with Dunnett's multiple comparison test; $p>0.05$ ) (data not shown). We infer that disulfide bonds were not formed between the M2-11' Cys and these M3 residues. Furthermore, we infer that these M3 Cys mutants did not form disulfide bonds with endogenous cysteine residues. Thus, we conclude that the effects described in the previous sections with the double Cys mutants containing the M2$12^{\prime}$ Cys arose because of disulfide bond formation between the M2-12' Cys and the corresponding M3 Cys.

\section{Homology modeling}

The first step in constructing a homology model is to align the respective sequences. As noted in Introduction, this is easy for ACh and $\mathrm{GABA}_{\mathrm{A}} \mathrm{M} 1$ and $\mathrm{M} 2$ segments because of the presence of a series of absolutely conserved residues (Fig. 1). Alignment of the M3 segments is more difficult. Depending on the number of sequences analyzed by multiple sequence alignment programs, either no gap or a one residue gap is created in the M2-M3 loop of the $\mathrm{GABA}_{\mathrm{A}}$ receptor sequences compared with the ACh receptor (AChR) sequences. Having identified the $\mathrm{GABA}_{\mathrm{A}} \alpha 1 \mathrm{M} 3$ residues that are in close proximity to $\alpha 1 \mathrm{M} 2-12^{\prime}$ as L301, F304, and A305, we can conclude that these residues should align with AChR residues in close proximity to $\alpha \mathrm{M} 2-12^{\prime}$ in the AChR structure (Unwin, 2005). These residues are ACh M3 $\alpha \mathrm{I} 289, \alpha \mathrm{T} 292$, and $\alpha \mathrm{V} 293$. These residues align with the $\mathrm{GABA}_{\mathrm{A}}$ receptor $\mathrm{M} 3$ residues that we identified if one assumes a one residue gap in the M2-M3 loop as shown in Figure 1.

We constructed homology models (see Materials and Methods) with no or one residue gaps in the M2-M3 loop (Fig. 6, compare $A, B)$. The channel-lining $\mathrm{M} 2$ residues are in good agreement with our previous substituted cysteine accessibility results (Xu and Akabas, 1993, 1996). The lack of the 1 aa gap in the M2-M3 loop introduces a $100^{\circ}$ rotation of the M3 segment residues. Consequently, the face of M3 that apposes M2 is made up of different amino acids in both models. Based on our crosslinking results, we infer that the alignment with the 1 aa gap in the M2-M3 loop must be used to thread the $\mathrm{GABA}_{\mathrm{A}}$ receptor $\alpha 1$ subunit onto the AChR structure. This suggests that the M2-M3 loop is one residue shorter in the $\mathrm{GABA}_{\mathrm{A}}$ receptor compared with 
A

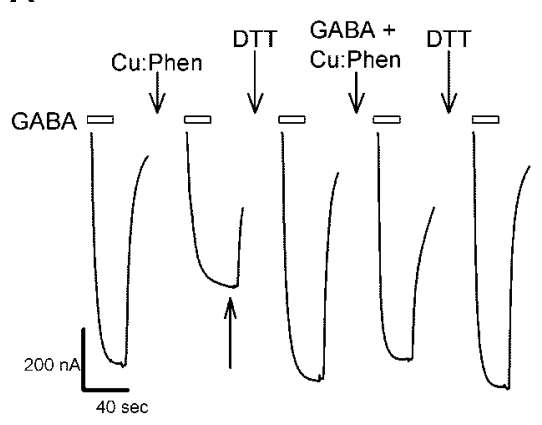

B

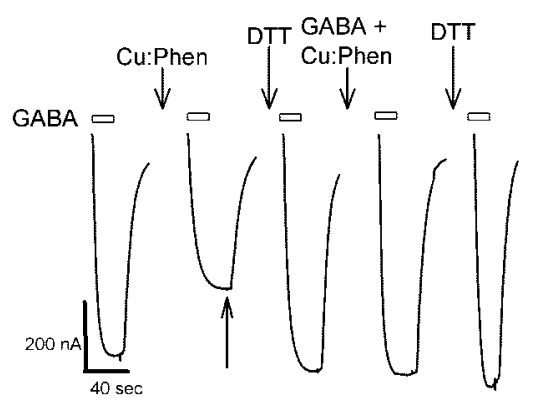

C

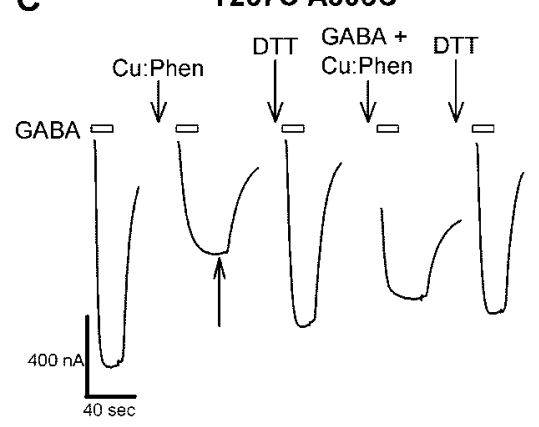

D

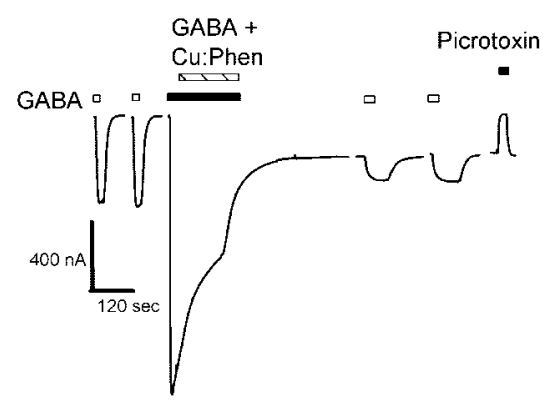

Figure 5. Effect of 2 min application of 10:20 $\mu \mathrm{M}$ Cu:Phen applied in the presence or in the absence of GABA on GABA-induced currents from oocytes expressing 12' Cys mutants. $\boldsymbol{A}, \boldsymbol{B}, \operatorname{In} \alpha 1 \mathrm{~T} 267 \mathrm{C}-\mathrm{L} 301 \mathrm{C}(\boldsymbol{A})$-and in $\alpha 1 \mathrm{~T} 267 \mathrm{C}-\mathrm{F} 304 \mathrm{C}(\boldsymbol{B})$-containing receptors, a 2 min application of $C u$ :Phen in the absence of GABA inhibited the subsequent GABA currents. This inhibition was reversed by DTT. A subsequent 2 min application of $\mathrm{Cu}$ :Phen in the presence of $\mathrm{EC}_{80} \mathrm{GABA}$ did not inhibit the subsequent $\mathrm{GABA}$ currents. An additional DTT application did not change the current size. Reagents were applied at the downward arrows. Currents are not shown during reagent applications. C, In $\alpha 1 T 267 C-A 305 C$ receptors, a 2 min application of Cu:Phen in the absence of GABA inhibited the subsequent GABA current. Reduction with DTT reversed the inhibition of the GABA current. A subsequent 2 min application of $\mathrm{Cu}$ :Phen in the presence of GABA had two effects on the following GABA currents. A large increase in the holding current was observed (note the level at which the subsequent GABA current begins), and the magnitude of the subsequent GABA current was significantly reduced. It is notable that the magnitude of the total current, the sum of the holding current and the GABA-induced current, was similar to the GABA current before the Cu:Phen/GABA application. The increased holding current and the reduced GABA current were reversed by a subsequent reduction with DTT. $\boldsymbol{D}$. Currents from an oocyte expressing $\alpha 1 T 267 \mathrm{C}$ A305C. Application and washout of Cu:Phen in the presence of GABA caused a significant increase in the holding current and a reduction in the GABA test current. The increased holding current was inhibited by application of $50 \mu \mathrm{m}$ picrotoxin. All GABA current traces represent stable currents: two subsequent GABA currents were not different by $>10 \%$. Only one is shown for the sake of clarity. Currents during reagent application are not shown. The bars above the traces indicate the duration of application of $G A B A$; the arrows indicate the application of the given reagent.

the ACh and $5-\mathrm{HT}_{3}$ receptor subunits. The functional consequences of this remain to be investigated.

\section{Discussion}

These results have important implications for Cys-loop receptor structure-function. First, the closed state disulfide bonds provide an experimental basis for alignment of $\mathrm{GABA}_{\mathrm{A}}$ and $\mathrm{ACh} \mathrm{M} 3$ segments, an essential step to constructing realistic $\mathrm{GABA}_{\mathrm{A}}$ homology models based on the $4 \AA$ AChR structure. This will provide a molecular framework for interpreting the effects of $\mathrm{GABA}_{\mathrm{A}}$ mutations on general anesthetic efficacy. Second, disulfide bond formation in the presence of GABA that increases spontaneous channel opening may provide insight into the conformational changes that M2 channel-lining segments undergo during channel opening in $\mathrm{GABA}_{\mathrm{A}}$ and other Cys-loop receptors.

Homology modeling offers the possibility of applying to $\mathrm{GABA}_{\mathrm{A}}$ receptors the recent advances in our understanding of ACh receptor structure. It is, however, essential to align correctly the $\mathrm{ACh}$ and $\mathrm{GABA}_{\mathrm{A}}$ sequences. In the transmembrane domain, absolutely conserved residues in and flanking M1 and M2 facili- tate correct alignment but depending on the number of sequences aligned, multiple sequence alignment programs introduce a gap in the M2-M3 loop (Fig. 1). This, coupled with the low sequence identity in M3, makes it difficult to align the ACh and $\mathrm{GABA}_{\mathrm{A}} \mathrm{M} 3$ segments. We used an unbiased search to determine the proximity between M2 and M3 residues. In the closed state, disulfide bonds formed spontaneously between M2-12', $\alpha 1 \mathrm{~T} 267 \mathrm{C}$, and both M3 $\alpha 1 \mathrm{~L} 301 \mathrm{C}$ and $\alpha 1 \mathrm{~F} 304 \mathrm{C}$ and could be induced with $\alpha 1 \mathrm{~A} 305 \mathrm{C}$. These three residues lie on one face of the M3 helix. In the closed state, this face of M3 lies in close proximity to M2 (Fig. 6). When the M2 Cys was moved to the adjacent position $\alpha 1 \mathrm{M} 266 \mathrm{C}\left(11^{\prime}\right)$, which should face M1, oxidation had no effect on any of these M3-Cys mutants, confirming the specificity of the reaction between M2$12^{\prime}$ Cys and these M3 cysteines. In our homology model, based on the AChR structure (Unwin, 2005), the M2-12' $\alpha$ carbon is within $10 \AA$ of the $\alpha$ carbons of these three M3 residues (Fig. 6). In a disulfide bond, the $\alpha$ carbons can be separated by at most 5.6 (Careaga and Falke, 1992). This implies that $4-5 \AA$ relative movements of M2 and M3 would bring these positions into sufficiently close proximity to permit disulfide bond formation. Previously, we showed that M2 undergoes even larger translational movements at the $20^{\prime}$ level (Horenstein et al., 2005) that are facilitated by the loose protein packing around the extracellular one-half of M2 (Goren et al., 2004; Unwin, 2005). Because disulfide bonds formed spontaneously with L301C and F304C, we infer that the collision frequency of M2-12' with these positions was higher and/or the orientation was more favorable than with $\mathrm{A} 305 \mathrm{C}$ (Fig. $6 C-E, G$ ). In the Torpedo AChR structure, the $\alpha$ subunit M3 residues in close proximity to M2-12' are I289, T292, and V293 (Unwin, 2005). To align these $A C h$ and $\mathrm{GABA}_{\mathrm{A}}$ residues, a single gap must be introduced into the M2-M3 loop (Figs. 1, 6). Thus, despite the cogent rationale offered recently for a two residue gap in the M2-M3 loop (Ernst et al., 2005), it is not supported by our current experiments. Furthermore, our results imply that the relative depths of the M2 and M3 segments in the 2BG9 AChR structure are correct (Unwin, 2005).

Our results place limits on the extent of thermal motion occurring in this region of M3. The absence of disulfide bond formation with residues on the backside of M3 implies that M3 does not undergo significant rotational motion in the closed state. The absence of disulfide bond formation between M2-12' C and M3V297C, the residue on the reactive face one helical turn more extracellular than L301, implies that in the closed state the upward displacement (i.e., perpendicular to the membrane plane) of M2 relative to M3 is less than $\sim 5 \AA$. The $\alpha$-carbon separation between M2-12' and V297 is $10 \AA$ (Fig. 6G). Furthermore, $\alpha 1$ Cys293, an endogenous cysteine on the same helical face one 
turn above V297 (Fig. 6G), did not form a disulfide bond with the M2-12' Cys because neither DTT nor Cu:Phen had any effect on the single M2-12'Cys mutant. These results, combined with the lack of reaction of sulfhydryl-reactive reagents with $\mathrm{M} 3$ engineered Cys residues below $\alpha 1 \mathrm{Y} 294 \mathrm{C}$ in the closed state (Williams and Akabas, 1999) suggest that M3 has limited thermal motion and water surface accessibility in the closed state. In contrast, M2 undergoes significant thermal motion in the closed state, particularly above $12^{\prime}$ (Horenstein et al., 2001; Bera and Akabas, 2005; Horenstein et al., 2005). These results also place limits on the potential rotational movement of $\mathrm{M} 2$, because no disulfide bonds formed between the M2-11' position and any of the M3 Cys mutants.

GABA activation altered the orientation and/or relative position of M2 and M3. Previously, we showed that GABA activation increased the water accessibility of several M3 positions including L301, suggesting that $\mathrm{M} 3$ and/or its surroundings underwent a conformational change during gating (Williams and Akabas, 1999). With GABA, disulfide bonds did not form or formed at a significantly slower rate between $\mathrm{M} 2-12^{\prime} \mathrm{C}$ and either $\mathrm{L} 301 \mathrm{C}$ or F304C (Fig. 5A,B). In contrast, an $\alpha 1$ T267C-A305C disulfide bond formed in the presence and absence of GABA, but the functional effect was quite different: When induced in the absence of GABA, the subsequent GABA currents were inhibited, whereas in the presence of GABA, it caused a significant increase in the spontaneous open probability that was inhibited by picrotoxin and reversed by DTT (Fig. $5 C, D$ ). We infer that, in the closed and activated states, disulfide bond formation trapped the receptor in two distinct conformations that were not interchangeable after bond formation. This conformational change could involve an $\sim 5 \AA$ translational movement of M2 toward the M1 segment in the counterclockwise adjacent subunit (looking from the extracellular side).

How could an $\alpha 1$ T267C-A305C disulfide bond increase spontaneous opening? In the closed state, the M2 segments probably fluctuate continuously between their closed and open conformations, although predominantly in the closed conformation. Presumably, spontaneous opening and ion conduction only occurs when all five M2 segments are in the open conformation, which rarely occurs in the absence of GABA. We infer that the $\alpha 1 \mathrm{~T} 267 \mathrm{C}-\mathrm{A} 305 \mathrm{C}$ disulfide bond formed in the presence of GABA holds the two $\alpha 1 \mathrm{M} 2$ segments in a conformation similar to their open conformation. Thus, after disulfide bond formation, spontaneous opening would only require the remaining three M2 segments to simultaneously enter the open conformation. This would significantly increase the spontaneous open probability. Alternatively, the conformation with the $\alpha$ subunit disulfide
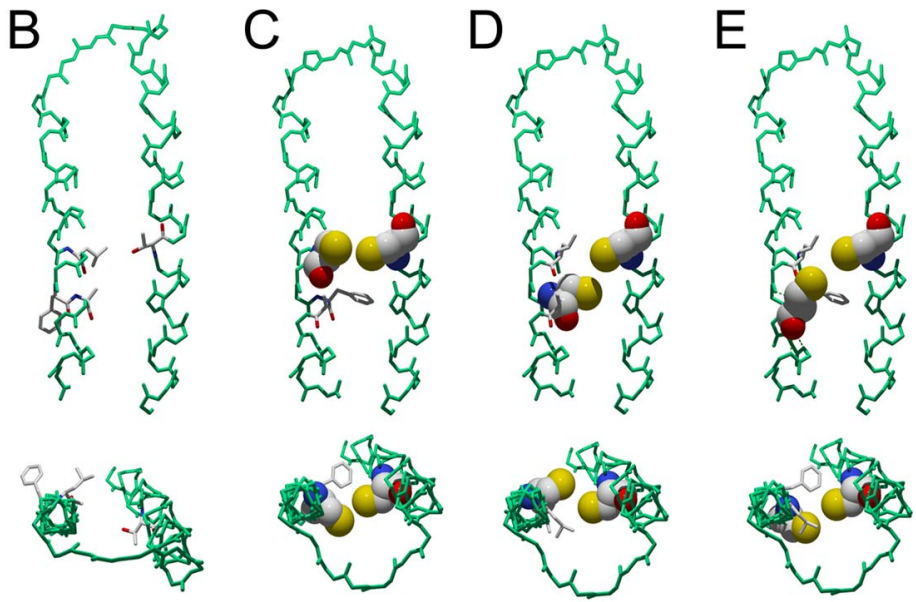

wt - No gap

T267C-L301C

T267C-F304C

T267C-A305C

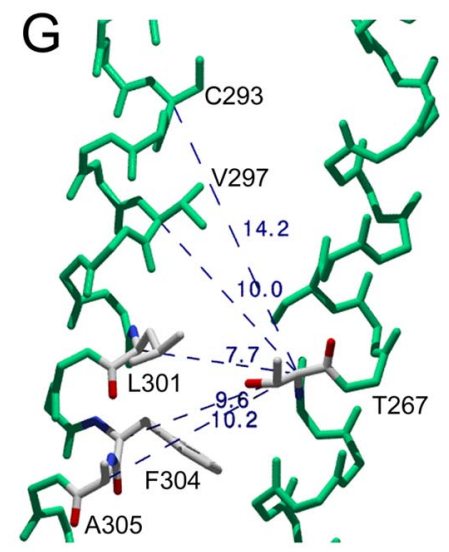

wt - 1 gap

Figure 6. Homology model. A homology model of the $\mathrm{GABA}_{\mathrm{A}}$ receptor $\alpha 1$ subunit was generated using the nicotinic $\mathrm{ACh}$ receptor structure (PDB number $2 \mathrm{BG} 9$ ) as a template. The $\mathrm{M} 2$ and $\mathrm{M} 3$ helices and the connecting $\mathrm{M} 2-\mathrm{M} 3$ loop are shown in and $\mathrm{M} 3$ segments of wt and mutant receptors are shown from the side (top) and top (bottom). $\boldsymbol{A}$ shows a model with a 1 aa gap are not in close proximity in this model. $C-G$ were generated using the model containing a single gap in the M2-M3 loop as shown in $\boldsymbol{A}$. $\boldsymbol{C}-\boldsymbol{E}$ illustrate the proximity of the pairs of residues that formed disulfide bonds. van der Waals surfaces of Cys substituted at these positions are shown. $\boldsymbol{F}$, Mutations at M2-15' S270 and M3 A291 alter the action of general anesthetics. van der Waals surfaces of Cys substituted at these positions are shown. The $\alpha$ carbons are separated by $\sim 15 \AA$, making it unlikely that they are part of a single binding site. $\mathbf{G}$ shows the $\alpha$-carbon separation of the $\mathrm{M} 2-12^{\prime}$ residue and several $\mathrm{M} 3$ residues.

bonds might induce a conformational change in the M2 segments of the neighboring subunits. We cannot distinguish between these possibilities, although we favor the former. Previously, we found that spontaneous channel opening increased when a disulfide bond formed in the presence of GABA between M2-6' Cys in adjacent subunits (Horenstein et al., 2001). Thus, there are multiple positions where disulfide bond formation in the GABAactivated state leads to increased spontaneous channel opening. These may provide insight into the conformational changes that occur during channel activation.

$\mathrm{GABA}_{\mathrm{A}} \mathrm{M} 2-15^{\prime}$ mutations alter general anesthetic potentiation in both heterologous expression systems and knock-in mice (Belelli et al., 1997; Mihic et al., 1997; Jurd et al., 2003). Mutations of residues aligned with M3- $\alpha 1 \mathrm{~A} 291$ also alter general anesthetic potentiation (Mihic et al., 1997; Krasowski et al., 2001; Bali and Akabas, 2004). These two positions were widely assumed to be 
part of a single anesthetic binding site; however, the intravenous anesthetic propofol only protected a Cys at the $\beta 2 \mathrm{M} 3$ site from modification by sulfhydryl reagent, suggesting that they were separate sites (Bali and Akabas, 2004). Using unrelated four-helixbundle proteins as templates, models were constructed that placed these two positions in close proximity (Trudell and Bertaccini, 2002). Other investigators, using the effects of $\mathrm{Hg}^{2+}$ on Cys mutants substituted at the aligned positions in glycine receptors, concluded that a single $\mathrm{Hg}^{2+}$ ion could bind simultaneously to engineered Cys at both positions (Lobo et al., 2004). In our homology model, based on the 2BG9 coordinates and our current results, the $\alpha$ carbons of $\alpha 1 \mathrm{M} 2-15^{\prime}$ and M3- $\alpha 1 \mathrm{~A} 291$ are separated by $15.6 \AA$ (Fig. $6 F$ ). This suggests that they are not part of a single binding site. The lack of rotation of M3 and the limited vertical movement make it unlikely that thermal motion could bring these positions into close proximity. Given their separation, we doubt that a single $\mathrm{Hg}^{2+}$ could simultaneously bind to Cys at both sites (Lobo et al., 2004). More likely, each Cys bound separate $\mathrm{Hg}^{2+}$ ions leading to the reported effects.

Our results provide experimental evidence for the correct threading of the $\mathrm{GABA}_{\mathrm{A}} \mathrm{M} 3$ segment onto the AChR structure. They support the ClustalW sequence alignment with a one residue gap in the $\mathrm{GABA}_{\mathrm{A}}$ and glycine $\mathrm{M} 2-\mathrm{M} 3$ loops compared with the ACh and 5-HT3 receptors. How this alters interactions between this loop and the extracellular domain that are critical for channel gating (Kash et al., 2003; Lummis et al., 2005; Reeves et al., 2005) remain to be elucidated. The development of more realistic $\mathrm{GABA}_{\mathrm{A}}$ receptor homology models will lead to a better understanding of general anesthetic binding and of the conformational changes induced by agonist activation and by anesthetics.

\section{References}

Bali M, Akabas MH (2004) Defining the propofol binding site location on the GABAA receptor. Mol Pharmacol 65:68-76.

Belelli D, Lambert JJ, Peters JA, Wafford K, Whiting PJ (1997) The interaction of the general anesthetic etomidate with the gamma-aminobutyric acid type A receptor is influenced by a single amino acid. Proc Natl Acad Sci USA 94:11031-11036.

Bera AK, Akabas MH (2005) Spontaneous thermal motion of the GABA(A) receptor M2 channel-lining segments. J Biol Chem 280:35506-35512.

Brejc K, van Dijk WJ, Klaassen RV, Schuurmans M, van Der Oost J, Smit AB, Sixma TK (2001) Crystal structure of an ACh-binding protein reveals the ligand-binding domain of nicotinic receptors. Nature 411:269-276.

Careaga CL, Falke JJ (1992) Thermal motions of surface alpha-helices in the D-galactose chemosensory receptor. Detection by disulfide trapping. J Mol Biol 226:1219-1235.

Celie PH, van Rossum-Fikkert SE, van Dijk WJ, Brejc K, Smit AB, Sixma TK (2004) Nicotine and carbamylcholine binding to nicotinic acetylcholine receptors as studied in AChBP crystal structures. Neuron 41:907-914.

Cromer BA, Morton CJ, Parker MW (2002) Anxiety over GABA(A) receptor structure relieved by AChBP. Trends Biochem Sci 27:280-287.

Ernst M, Bruckner S, Boresch S, Sieghart W (2005) Comparative models of GABAA receptor extracellular and transmembrane domains: important insights in pharmacology and function. Mol Pharmacol 68:1291-1300.

Goren EN, Reeves DC, Akabas MH (2004) Loose protein packing around the extracellular half of the GABAA receptor $\beta 1$ subunit M2 channellining segment. J Biol Chem 279:11198-11205.

Guex N, Peitsch MC (1997) SWISS-MODEL and the Swiss-PdbViewer: an environment for comparative protein modeling. Electrophoresis $18: 2714-2723$.

Hevers W, Lüddens H (1998) The diversity of $\mathrm{GABA}_{\mathrm{A}}$ receptors. Pharmacological and electrophysiological properties of $\mathrm{GABA}_{\mathrm{A}}$ channel subtypes. Mol Neurobiol 18:35-86.

Horenstein J, Akabas MH (1998) Location of a high affinity $\mathrm{Zn}^{2+}$ binding site in the channel of alphalbetal gamma-aminobutyric acid A receptors. Mol Pharmacol 53:870-877.

Horenstein J, Wagner DA, Czajkowski C, Akabas MH (2001) Protein mobility and GABA-induced conformational changes in $\mathrm{GABA}_{\mathrm{A}}$ receptor pore-lining M2 segment. Nat Neurosci 4:477-485.

Horenstein J, Riegelhaupt P, Akabas MH (2005) Differential protein mobility of the gamma-aminobutyric acid, type $\mathrm{A}$, receptor alpha and beta subunit channel-lining segments. J Biol Chem 280:1573-1581.

Imoto K, Busch C, Sakmann B, Mishina M, Konno T, Nakai J, Bujo H, Mori Y, Fukuda K, Numa S (1988) Rings of negatively charged amino acids determine the acetylcholine receptor channel conductance. Nature 335:645-648.

Jurd R, Arras M, Lambert S, Drexler B, Siegwart R, Crestani F, Zaugg M, Vogt KE, Ledermann B, Antkowiak B, Rudolph U (2003) General anesthetic actions in vivo strongly attenuated by a point mutation in the GABA(A) receptor beta3 subunit. FASEB J 17:250-252.

Karlin A (2002) Emerging structure of the nicotinic acetylcholine receptors. Nat Rev Neurosci 3:102-114

Kash TL, Jenkins A, Kelley JC, Trudell JR, Harrison NL (2003) Coupling of agonist binding to channel gating in the $\mathrm{GABA}(\mathrm{A})$ receptor. Nature 421:272-275.

Kobashi K (1968) Catalytic oxidation of sulfhydryl groups by $o$-phenanthroline copper complex. Biochim Biophys Acta 158:239-245.

Krasowski MD, Nishikawa K, Nikolaeva N, Lin A, Harrison NL (2001) Methionine 286 in transmembrane domain 3 of the GABAA receptor beta subunit controls a binding cavity for propofol and other alkylphenol general anesthetics. Neuropharmacology 41:952-964.

Krezel A, Latajka R, Bujacz GD, Bal W (2003) Coordination properties of tris(2-carboxyethyl)phosphine, a newly introduced thiol reductant, and its oxide. Inorg Chem 42:1994-2003.

Le Novere N, Changeux JP (1999) The ligand gated ion channel database. Nucleic Acids Res 27:340-342.

Lester HA, Dibas MI, Dahan DS, Leite JF, Dougherty DA (2004) Cys-loop receptors: new twists and turns. Trends Neurosci 27:329-336.

Lobo IA, Trudell JR, Harris RA (2004) Cross-linking of glycine receptor transmembrane segments two and three alters coupling of ligand binding with channel opening. J Neurochem 90:962-969.

Lummis SC, Beene DL, Lee LW, Lester HA, Broadhurst RW, Dougherty DA (2005) Cis-trans isomerization at a proline opens the pore of a neurotransmitter-gated ion channel. Nature 438:248-252.

Mihic SJ, Ye Q, Wick MJ, Koltchine VV, Krasowski MD, Finn SE, Mascia MP, Valenzuela CF, Hanson KK, Greenblatt EP, Harris RA, Harrison NL (1997) Sites of alcohol and volatile anaesthetic action on GABA(A) and glycine receptors. Nature 389:385-389.

Miller C (1989) Genetic manipulation of ion channels: a new approach to structure and mechanism. Neuron 2:1195-1205.

Miyazawa A, Fujiyoshi Y, Unwin N (2003) Structure and gating mechanism of the acetylcholine receptor pore. Nature 423:949-955.

Reeves DC, Jansen M, Bali M, Lemster T, Akabas MH (2005) A role for the $\beta 1-\beta 2$ loop in the gating of 5- $\mathrm{HT}_{3}$ receptors. J Neurosci 25:9358-9366.

Schwede T, Kopp J, Guex N, Peitsch MC (2003) SWISS-MODEL: an automated protein homology-modeling server. Nucleic Acids Res 31:3381-3385.

Trudell JR, Bertaccini E (2002) Molecular modelling of specific and nonspecific anaesthetic interactions. Br J Anaesth 89:32-40.

Trudell JR, Bertaccini E (2004) Comparative modeling of a GABAA alpha1 receptor using three crystal structures as templates. J Mol Graph Model 23:39-49.

Unwin N (2005) Refined structure of the nicotinic acetylcholine receptor at $4 \AA$ resolution. J Mol Biol 346:967-989.

Williams DB, Akabas MH (1999) Gamma-aminobutyric acid increases the water accessibility of M3 membrane-spanning segment residues in gamma-aminobutyric acid type A receptors. Biophys J 77:2563-2574.

Xu M, Akabas MH (1993) Amino acids lining the channel of the gammaaminobutyric acid type A receptor identified by cysteine substitution. J Biol Chem 268:21505-21508.

Xu M, Akabas MH (1996) Identification of channel-lining residues in the M2 membrane-spanning segment of the $\mathrm{GABA}_{\mathrm{A}}$ receptor alpha1 subunit. J Gen Physiol 107:195-205. 